\title{
Strengthening of Structures Damaged by the Azores Earthquake of 1988
}

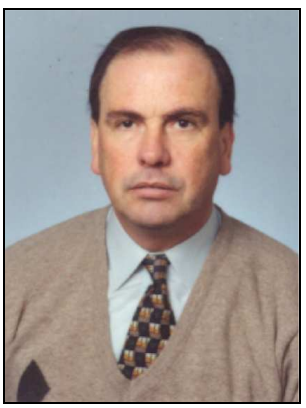

Aníbal COSTA

Associate Professor FEUP

Porto

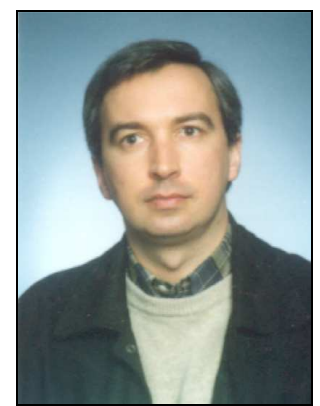

António Arêde Assistant Professor FEUP Porto

\section{SUMMARY}

This paper addresses repair and strengthening techniques proposed for the rehabilitation of small buildings on Faial Island, Azores, hit and damaged by the Azores earthquake on 9 July 1998. A brief description is provided of the construction type and practice in the island, highlighting the main type of houses. Due to the lack of relevant information concerning construction material data, experimental tests were performed in situ, involving static and dynamic measurements. The experimental campaign is addressed and the main results are highlighted. These results served as input data for numerical seismic analysis of a number of house structures, which provided validation support for the design of strengthening strategies. One of such analysis is presented herein. The basic aspects of the proposed strengthening techniques are briefly presented and discussed, focusing on their practical application.

\section{INTRODUCTION}

The observation of the social reality of Azores islands, as the Faial island, reveals an economy essentially based on family subsistence of people who long ago resigned themselves to "accept" earthquakes as inevitable. This scenario pointed out the preservation of traditional construction and techniques as one of the main premises for the rehabilitation of Faial small buildings hit by earthquakes in general and by the seismic crises of 9 July 1998, in particular.

The rehabilitation and strengthening strategy thus requires good knowledge about the buildings and their past alterations. In the context of the present work, an effort was made to obtain a 
good understanding of the traditional construction process and to gather an in-depth knowledge of the construction materials' characteristics in Faial island. This scope involved a broad inspection campaign covering several Faial buildings that were damaged by the earthquake of 9 July 1998.

Surveys provided essential data about types of buildings and traditional construction techniques, as well as the main types of observed earthquake damages, but also evidenced the difficulties in defining physical and mechanical characteristics of the existing masonry material. This conclusion led to the need of performing a set of experimental tests in order to obtain material data of major relevancy for numerical analysis that should support the design of structural strengthening.

The following sections thus give brief overviews on the construction reality of Faial island and on the basic aspects of the performed experimental campaign, emphasizing the modest means adopted in the in-situ tests. Next, the numerical analysis carried out are also referred, mainly focusing in one of the studied cases for which material data calibration was possible by comparison with in-situ ambient vibration measurements. Finally, the proposed strengthening options are presented taking into account the observed behaviour, the results obtained by the numerical simulation and the strong concern of trying to keep, as much as possible, the existing resistant elements and of using construction means compatible with the local economic reality.

\section{CONSTRUCTION TYPES AND PRACTICES IN FAIAL, AZORES}

Based on several surveys and inspections in various villages of Faial island, three types of construction were identified, namely:

- $\quad$ single storey rural houses, generally modest and located in flat rural areas, fig. 1;

- two storey semi-rural houses, more common in urban centres of rural wards, fig. 2;

- two or three storey urban buildings, located in urban quarters of towns, fig. 3.

The precise construction date of existing buildings is often difficult to establish; furthermore, many houses have been changed during their lifetime, having been rebuilt or modified due to previous earthquakes.

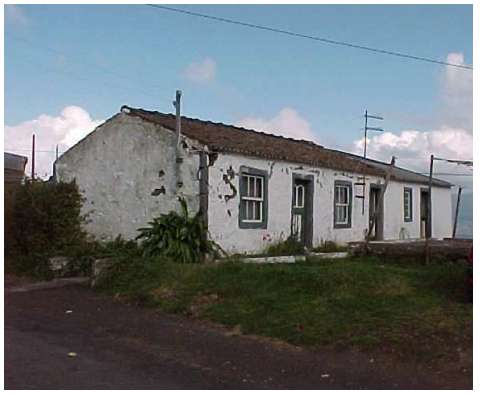

Fig. 1 - Rural house

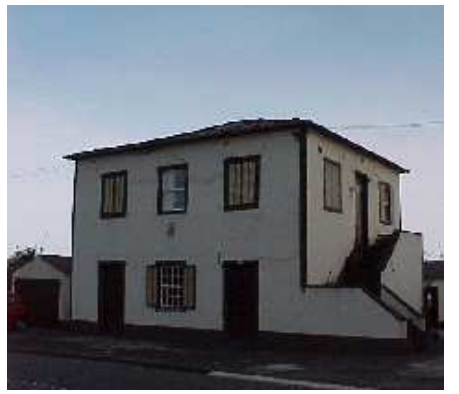

Fig. 2 - Semi-rural house

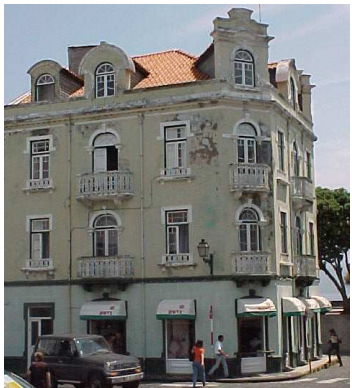

Fig. 3 - Urban house 
The principal structural elements usually consist of stone masonry walls, mainly external in the periphery of the building although some internal ones may be also found. Different ways of building external walls can be found, depending on the location (urban or rural) and on the owner's economic resources. Typically, the following types of walls commonly exist in the island [1]: $i$ ) upper quality masonry walls, built with regular trimmed stone along alternate rows placed parallel to the wall and with cross-beams perpendicular to the wall; $i$ ) irregular stone masonry walls with "burnt stone" blocks placed and treated with more or less care, depending on the master builder, where stone interlock plays the important role to ensure good performance whilst voids are filled with rubble material; iii) two-leaf or double stone masonry walls made of selected stones slightly longer than half thickness of the wall, where the stones are interlocked and form well defined and spaced layers less then $1 \mathrm{~m}$ high.

Rural areas of Faial mostly have exterior walls of the second and third types, which are about 65 to $70 \mathrm{~cm}$ thick. Interior walls are normally made of wood plastered in both faces, either with a hollow interior or filled with $2.50 \mathrm{~cm}$ thick boards comprising a latticework that is plastered with lime, sand and clay mortar. Sometimes the interior walls are also used for structural purposes, fig. 4.

Most houses have the same type of so-called "scissor" roof structure, fig. 5, with sloping beams (i.e. in the water flow direction) of various sizes, from $14 \times 5 \mathrm{~cm}^{2}$ to $19 \times 7 \mathrm{~cm}^{2}$, spaced at about $35 \mathrm{~cm}$ and supporting the roof lining. These beams are supported by a periphery horizontal tie beam, with about $10 \times 10 \mathrm{~cm}^{2}$ cross section, embedded in the top-end of the wall. The opposite walls supporting that tie beam are, in turn, connected by transversal ties, which may be wood trunks of irregular shape, somewhat round and with trimmed ends, or of a rectangular shape. A lining made of overlapping boards that support tiles, fig. 5, covers the roof frame.

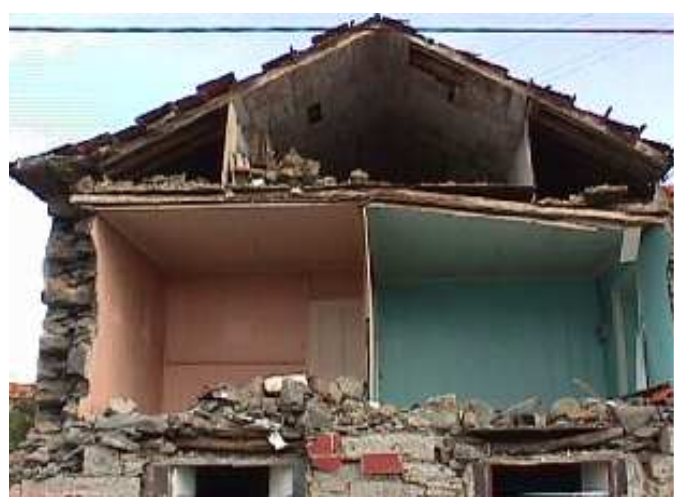

Fig. 4 - Aspect of the building's interior

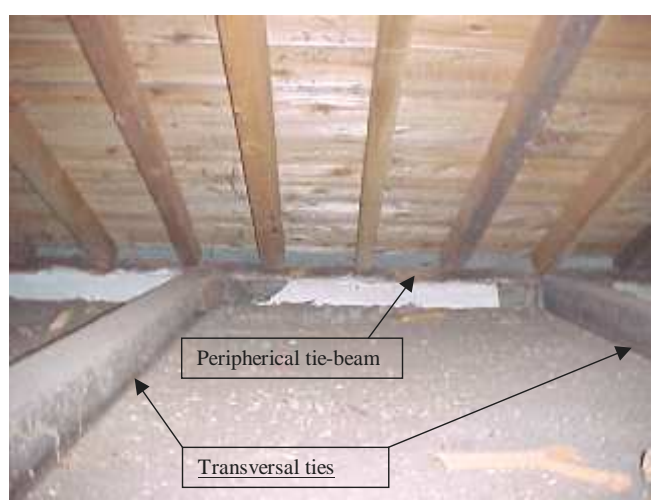

Fig. 5 - Structural "scissor" roof solution

\section{EXPERIMENTAL TESTS}

In-situ tests were performed at both local (element and material) and global (structural) levels in order to achieve adequate estimates of material properties. 
At the element and material level, tests were carried out on wall specimens taken from houses seriously damaged after the July 1998 earthquake. Aiming at obtaining estimates of material characteristics and testing some strengthening solutions, three panels were taken from wall portions between door and window openings. For each house, one panel was left unchanged and the two others were strengthened by means of two different techniques. One such technique consisted on first cleaning old existing plaster, then plastering with mortar properly filling voids in order to obtain a smooth surface, followed by placing a steel mesh fastened to both wall sides which was finally covered with a new plaster layer at least $3 \mathrm{~cm}$ thick. The other technique consisted in pouring cement grout through the wall top end, thereby filling the internal voids between stones, the grout having been made of cement, volcanic ash and water.

Results herein presented refer to tests on house A, which is partially schematized in fig. 6 both in plan view and in elevation. The panels are identified as: A1, for the original one; A2, for the steel mesh reinforced panel; and A3, for the poured grout reinforced panel.
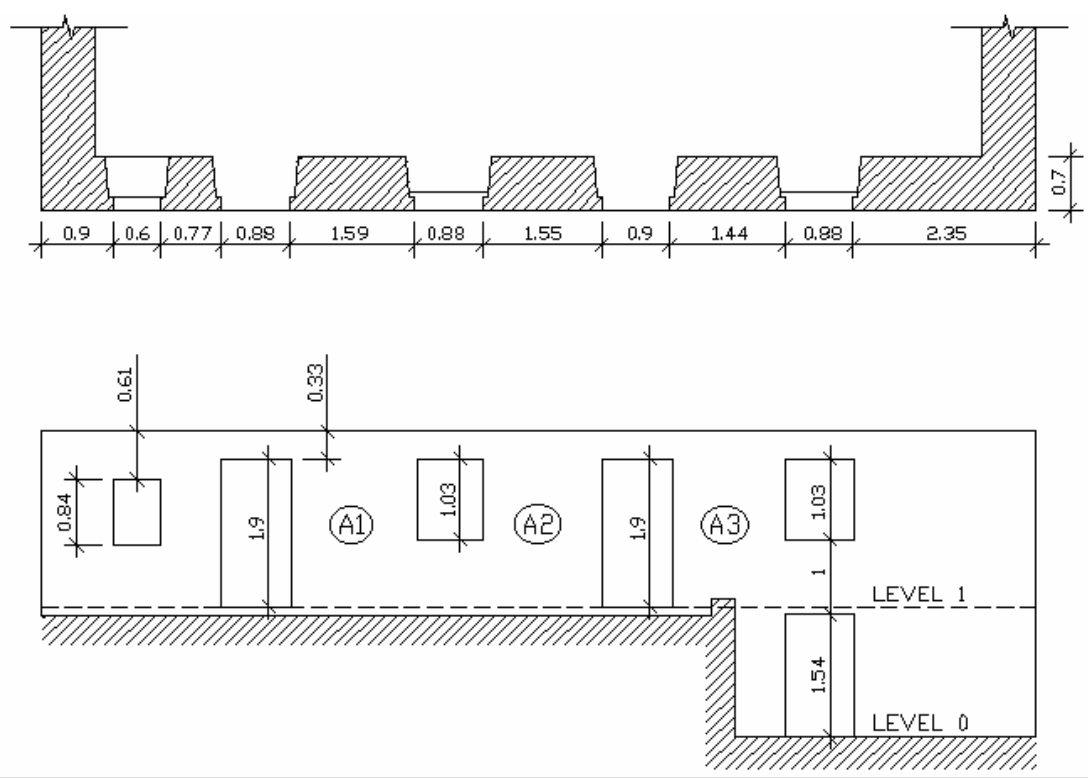

Fig. 6 - Partial schematic representation of the layout and elevation of house A

Auxiliary steel lattice structures were prepared to allow performing the panel tests, such that, as shown in fig. 7, with the application of vertical loads on the lattice, the panel could be horizontally loaded in the transverse direction near to its top end. Under oscillation, the load produces forced movement that amplifies the horizontal action on the wall and induces vibration on it. The auxiliary structure consists of HEB100 steel bars and allows an eccentricity of $1.0 \mathrm{~m}$ for the vertical load.

Loads were created by means of a metal bucket suspended from a steel cable and filled with sand, whose weight was placed in several stages and always monitored. The metal bucket was provided with a bottom closure to allow discharging the sand, also in various stages. 
Instruments were used to evaluate the static and dynamic response of the wall, from which the mechanical characteristics of the masonry were derived. These instruments included mechanical dial gauges, suitable for the static loading stages [2], and an accelerograph to obtain records of the dynamic response. The method of applying test loads, measuring displacements and recording vibrations is described in [3].

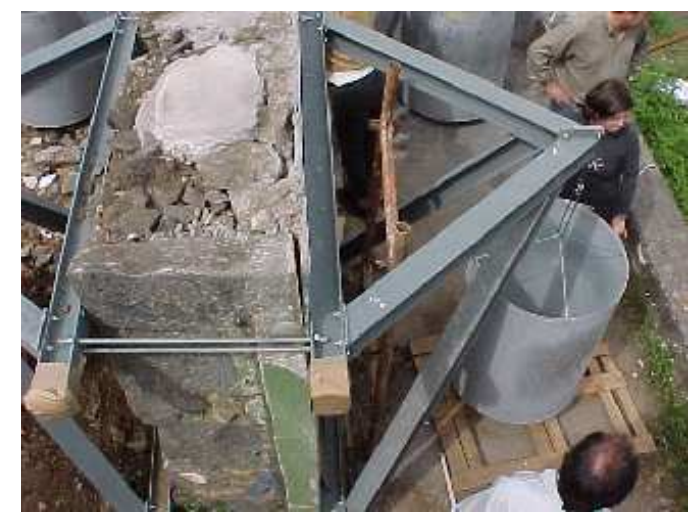

a) General view

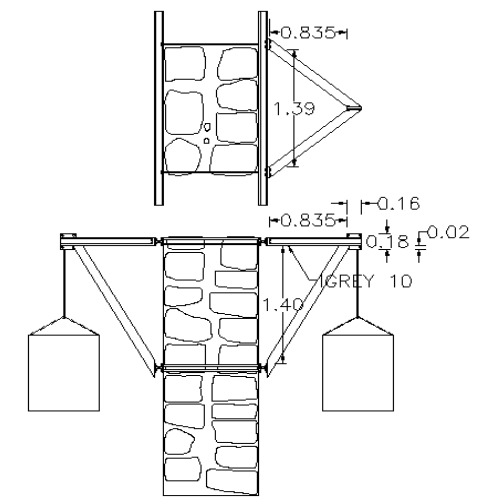

b) Schematic representation

Fig. 7 - The auxiliary steel structure used in the tests.

The vibration recordings and the respective analyses are an indirect technique of estimating the mechanical elasticity properties of a given structure. Therefore, several acceleration plots were obtained for each panel and for different load stages upon the application of an impact on the panel. Fig. 8-a shows one of these records for wall A1, without horizontal load and subject to an impact in the transversal direction (normal to the wall). That signal was processed to estimate the predominant frequencies and damping, respectively, by selecting amplitude peaks of the signal FFT (Fast Fourier Transform), fig. 8-b, and by adjusting an exponential curve to the fading response, fig. 8-c.

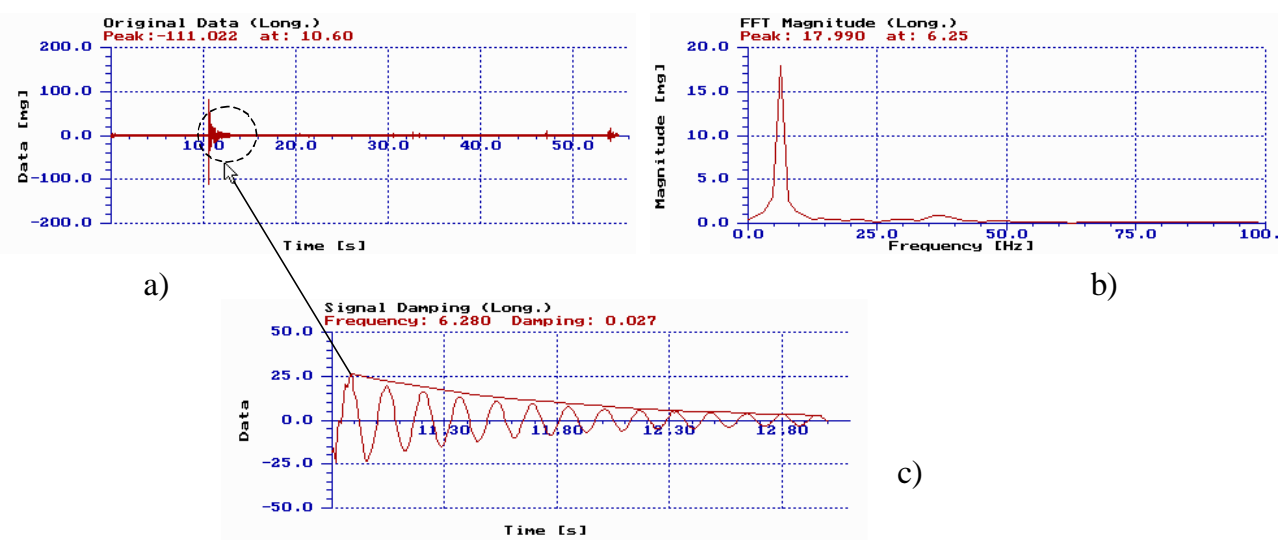

Fig. 8 - Response records due to impacts in the normal direction to the wall. a) acceleration;

b) estimated frequency through the FFT and c) estimated damping 
This procedure was used for the three directions, transversal, longitudinal and vertical, thus providing graphs of the same type for the other walls [4] that were used to obtain frequencies and damping values of each tested panel. These test results are summarised in Table I.

Table I - Frequency and damping values obtained from tests on house A

\begin{tabular}{|c|c|c|c|c|c|c|}
\hline \multirow[b]{2}{*}{ Panel } & \multicolumn{2}{|c|}{ Transversal Direction } & \multicolumn{2}{|c|}{ Longitudinal Direction } & \multicolumn{2}{|c|}{ Vertical Direction } \\
\hline & $\begin{array}{c}\text { Frequency } \\
\text { (Hertz) }\end{array}$ & $\begin{array}{c}\text { Damp. } \\
(\%)\end{array}$ & $\begin{array}{c}\text { Frequency } \\
\text { (Hertz) }\end{array}$ & $\begin{array}{c}\text { Damp. } \\
(\%)\end{array}$ & $\begin{array}{c}\text { Frequency } \\
\text { (Hertz) }\end{array}$ & $\begin{array}{c}\text { Damp. } \\
(\%)\end{array}$ \\
\hline A1 & 6.25 & 2.7 & 12.11 & 6.2 & 23.44 & 5.8 \\
\hline $\mathrm{A} 2$ & 9.38 & 3.5 & 17.97 & 3.3 & 26.50 & 3.9 \\
\hline A3 & 6.25 & 2.7 & 17.97 & 6.2 & 23.44 & 5.8 \\
\hline
\end{tabular}

The effectiveness of the strengthening technique used in the panel A2 (steel mesh in both wall sides) is quite apparent from the increased frequency values shown in Table I. By contrast, the technique adopted in panel A3 did not lead to a clear improvement of wall performance, although the longitudinal frequency tends to suggest some stiffness increase. This might be related with difficulties in ensuring that internal voids were effectively filled with the poured mortar.

The non-strengthened panel (A1) wall was the only one that collapsed when subject to a load much lower than those applied to walls A2 and A3. In fact, after the load of $5.40 \mathrm{kN}$ was reached, pronounced oscillation of panel A1 started occurring as a consequence of the bucket forced oscillating movement. This oscillation was followed by the panel wall collapse as shown in fig. 9.

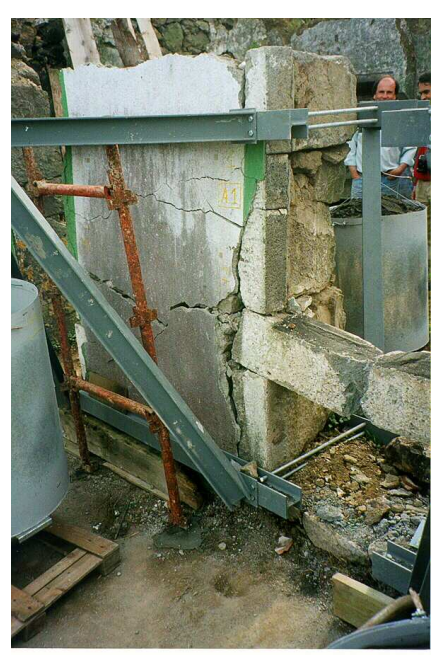

Fig. 9 - Collapse of panel A1

In order to estimate values of masonry mechanical characteristics, relations were established between the testing parameters and the properties of panel materials. Furthermore, it was also necessary to obtain a better knowledge of the panel interior filling material allowing to estimate the wall mass. This was accomplished by taking six bore samples from each wall for a series of laboratory tests through which the wall density was estimated.

The bore samples were $12 \mathrm{~cm}$ in diameter and of variable lengths, depending on the wall thickness and type. Those samples were the same length as the cylinder of the drilling machine where a whole stone occupied the boring area, whereas in other cases the length was only a few centimetres long. The average specific unit weight of each wall was thus obtained by the quotient between the bore sample weight and the volume of the extraction hole. Should the house A be considered as representative of Faial typical construction, the average specific unit weight of stone masonry can be taken about $18 \mathrm{kN} / \mathrm{m}^{3}$. 
The elasticity modulus values may be estimated on the basis of frequency values for the various panels. Therefore, assuming that the panel behaves as a cantilever, the frequency may be expressed as follows [5]:

$$
\omega=(1.875)^{2} \sqrt{E I / m l^{4}}
$$

where $\omega$ represents the panel angular frequency $(\mathrm{rad} / \mathrm{s}), E$ is the elasticity modulus, $I$ refers to the panel moment of inertia in the considered direction, $m$ is the panel mass and $l$ is its height. The use of this formula for the results of the three walls of house A leads to the elasticity modulus values shown in Table II.

Table II - Frequencies of vibration and elasticity modulus values for the panels of house A

\begin{tabular}{|c|c|c|c|c|}
\hline & \multicolumn{2}{|c|}{ Longitudinal Direction } & \multicolumn{2}{c|}{ Transversal Direction } \\
\hline Panel & $\mathrm{f}(\mathrm{Hz})$ & $\mathrm{E}(\mathrm{GPa})$ & $\mathrm{f}(\mathrm{Hz})$ & $\mathrm{E}(\mathrm{GPa})$ \\
\hline A1 & 12.11 & 0.17 & 6.25 & 0.22 \\
\hline A2 & 17.97 & 0.32 & 9.38 & 0.40 \\
\hline A3 & 17.97 & 0.39 & 6.25 & 0.18 \\
\hline
\end{tabular}

Another means of estimating the elasticity modulus was also adopted by recourse to the measured displacements in correspondence to a given applied load. Results and details on the adopted procedure can be found elsewhere [3].

A comparison was made of the load-deflection diagrams for the points close to the top end of the panels for the different strengthening solutions. This comparison evidenced better performance of the strengthened panels when compared to the original (non-strengthened) panel, which is due to the panel increased stiffness (a clear decrease was observed in displacement values for the same load) and strength.

Finally, at the global structure level, several measurement campaigns were performed in situ to identify the first frequencies in different types of buildings, some of them to be strengthened, the basic scope being the subsequent comparison with frequencies obtained by numerical modelling of those buildings. As for the panel tests, it was used an accelerograph (strong motion seismograph) GEOSYG GSR-18 with a 18-bit acquisition card and with its full scale adjusted to $50 \mathrm{~cm} / \mathrm{s}^{2}$. The measurements were taken by placing the device in the door span to capture vibration mode frequencies of the walls, which are the main structural resistant elements. Some results are shown and presented in the following section for due comparison with the corresponding numeric simulations.

\section{NUMERICAL ANALYSIS}

Several structural analyses were numerically carried out covering the three types of buildings referred in section 2. Numerical analyses were performed using two computer codes available on FEUP, based on the finite element method, allowing to account for static and dynamic loading within linear and non-linear behaviour domain. 
Despite the capabilities of these codes, the numerical analyses were done only for linear elastic behaviour, in order to configure a methodology applicable in the design context. Frequencies and vibration modes were first calculated, followed by time domain dynamic analysis for an actually recorded accelerogram.

Both solid and shell elements were adopted to simulate structural masonry elements, whilst wood rafters, beams and columns were modelled with classical beam elements. In particular, the building structure referred herein, the semi-rural two storey house, was numerically analysed with the computer code NLDYNA developed at FEUP [6], for which 3D solid elements were used to model the masonry walls, the stairs, the chimney and the roof. Bar elements were adopted to model the wood rafters in the floor and ceiling.

According to the aforementioned, the vibration modes were calculated for the semi-rural house (fig. 2), using first the material properties' values estimated from the in situ experimental tests [3]. Since for this structure the main vibration frequencies were also experimentally obtained in the transversal and longitudinal directions, these results were used to calibrate the stone masonry elasticity modulus in order to fit calculated and measured frequencies.

Table III summarises the values obtained experimentally and numerically using the NLDYNA computer code, evidencing an excellent agreement of results when an adjusted value of $\mathrm{E}=0.23 \mathrm{GPa}$ is adopted for the stone masonry of walls.

Table III - Measured and calculated frequencies (semi-rural two storey house)

\begin{tabular}{|c|c|c|}
\hline \multicolumn{3}{|c|}{ Frequencies (Hz) } \\
\hline & Transversal (N-S) & Longitudinal (E-W) \\
\hline Measured & 5.7 & 5.8 \\
\hline Numerical Simulation & 5.66 & 5.86 \\
\hline
\end{tabular}

Figures 10 and 11 show the two first vibration modal configurations obtained by numeric calculation, where the north-south component is dominant in the $1^{\text {st }}$ mode, whilst the east-west direction is preponderant in the $2^{\text {nd }}$ mode. Note, however, that these are not pure translations due to the presence of substantially stiff and local elements (stairs and chimney) responsible for some rotation. The third vibration mode (not illustrated) is essentially a rotational mode with $8.05 \mathrm{~Hz}$ frequency.

The similarity of measured and numeric simulation frequencies for the two vibration modes, with an adjusted elasticity modulus of $0.23 \mathrm{GPa}$, shows that the achieved stiffness calibration is realistic. This calibration is even more sustained because that value is well within the value range resulting from the experimental panel testing campaign [3]. 


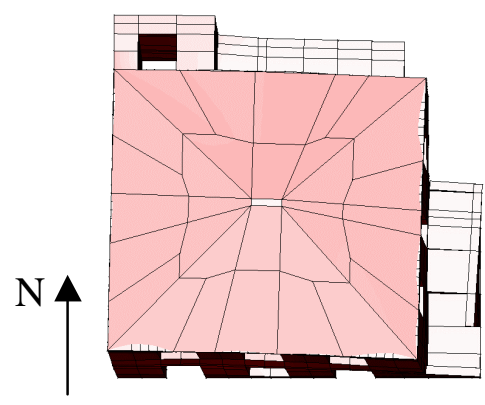

a)

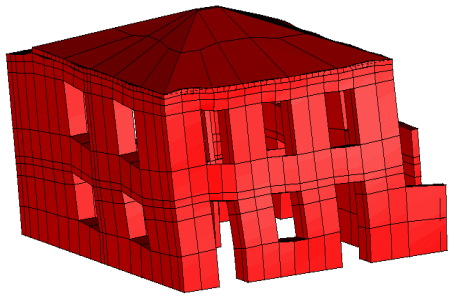

b)

Fig. 10 - Plan view (a) and perspective (b) of the $1^{\text {st }}$ vibration mode $(5.7 \mathrm{~Hz})$

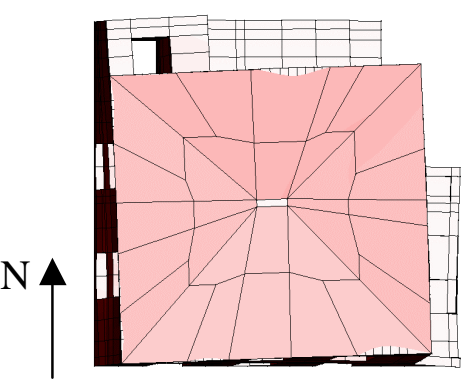

a)

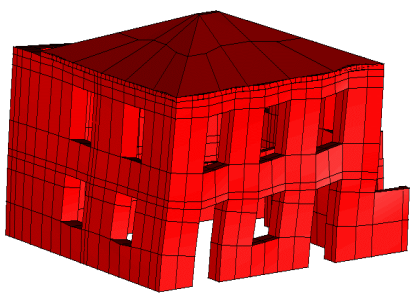

b)

Fig. 11 - Plan view (a) and perspective (b) of the $2^{\text {nd }}$ vibration mode $(5.8 \mathrm{~Hz})$

As already referred, the structural seismic response was numerically obtained by means of a linear dynamic analysis using the three components (N-S, E-W and vertical) of the 9 July 1998 earthquake in Faial [7]. Fig. 12 shows the two horizontal components of the records obtained at the foundations of the Prince of Monaco Observatory (located on the top of a hill at $60 \mathrm{~m}$ altitude), for an epicentral distance of about 10-15 km.
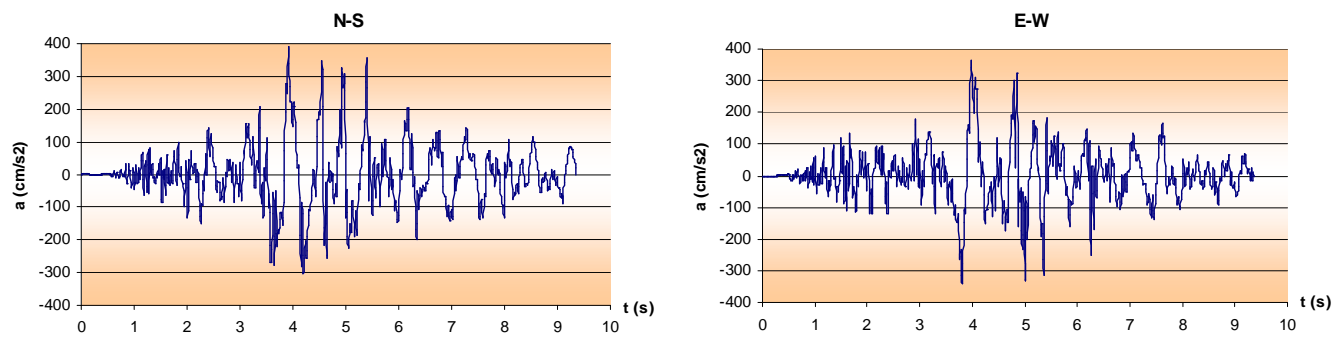

Figure 12 - Accelerograms for the 9 July 1998 earthquake (N-S and E-W directions)

These records of horizontal components correspond to a very characteristic earthquake in Azores (the so-called near-field earthquake) and have dominant frequencies in the interval from $1 \mathrm{~Hz}$ to $2.5 \mathrm{~Hz}$. The vertical component has considerable peak amplitudes $(0.32 \mathrm{~g})$ with frequency components between $6 \mathrm{~Hz}$ and $7 \mathrm{~Hz}$. 
Dynamic equations were numerically integrated in time domain using the Newmark method, and considering the Rayleigh formulation for the viscous-type structural damping, with a damping factor of about $5 \%$. Calculations allowed to obtain displacements at several points and to determine the walls' stresses and internal forces during the analysis time, as well as their corresponding maximal over time. It is worth reminding that the analysis was based on the results for that particular seismic action, which was 2.4 times greater than the standard seismic action [8]; bearing this in mind, the essential aspects of the analysis are summarised next.

The peak response values of this house showed that the maximum displacement of $1.2 \mathrm{~cm}$ (equivalent to a total drift of $0.2 \%$ ) occurred in one of the roof corners in the E-W direction. The overall displacement analysis confirms what had already been found through the vibration modes. There was a predominant translation in the two directions with a slight rotation around the chimney caused by its higher stiffness. By comparing the maximum horizontal acceleration of the structure (about $900 \mathrm{~cm} / \mathrm{s} 2$ ) with the peak ground acceleration, it is possible to estimate an overall dynamic amplification factor at about 2.5. The maximum tensile and compressive stresses were also obtained for the floor and roof beams (that may be used to connect the opposite exterior walls) in order to allow checking their safety. Further details about specific result values can be found elsewhere [9].

Peak values of the aforementioned results are, in themselves, relatively low. As already stated, these values resulted from a seismic action with peak acceleration greater than twice the standard peak acceleration [8]. This means that, in order to properly design the structural strengthening, those values may still be suitably scaled to levels compatible with the standard action. Since a linear elastic analysis was performed, in practice this means that the results must also be divided by a factor close to 2.4 , resulting in very low stresses. This aspect indicates that the structural strengthening is not likely to be very robust, but still should meet the fundamental requirement of ensuring an overall behaviour of the structure as a whole.

\section{5.- STRENGTHENING PROPOSALS}

Most buildings on Faial Island were built according to similar traditional construction methods, which explains why most seismic damages were, in general, also very similar. Therefore, the repair and strengthening techniques should also be made in line with a certain uniformity, except in some specific cases where different structural elements or construction processes were adopted or where possible existing pathologies require special care in particular elements.

The buildings proposed for strengthening are among those with significant damage, but whose repair is possible and acceptable in comparison with their value. The repair intervention herein proposed is set out in the framework of seismic safety, according to which the goal is not merely to repair damaged buildings but also to improve their future seismic resistance by making them as resistant as new buildings. Therefore, it must take into account the type of damages observed and must be based on a good understanding of what caused those damages in order to prevent them from occurring again in the future. Bearing in mind these premises and the observations of the actually occurred damage after the earthquake, the proposed 
rehabilitation methodologies were defined in such a way to improve stiffness and strength of masonry walls and to enhance wall bracing by recourse to adequate strengthening of floors and roof, whose connections to the walls must also be improved to perform efficiently.

The proposed strengthening mainly consists on reinforcing the walls, floors and roofs, though keeping the existing materials whenever possible. Special care is taken with connections between structural elements, in order to ensure a good global behaviour of the structure as a whole during seismic events.

According to the aforementioned, the proposed intervention to improve the integrity of stone masonry walls should start with a thorough cleaning of both wall faces, followed by a proper closing of all joints with mortar, part of which should be volcanic ash to make use of its pozzuolanic properties. Wherever possible, internal voids should be filled with liquid mortar [3], in order to improve bond of filling material. In walls to be plastered, a steel mesh (preferably stainless) is foreseen on each side of the wall and linked with connectors as illustrated in Figure 13-a; this mesh is then covered with a plaster layer, at least $3 \mathrm{~cm}$ thick, ready for final painting. In the cases of corners and openings, additional measures must be taken by placing steel folded plates or angle bars bolted to walls where stones do not intersect properly for good bracing.

Free walls, running parallel to roof and floor beams, must be braced at the roof and floor levels following the scheme shown in fig. 13-b. The bracing consists of a horizontal lattice supporting those walls and capable of transmitting that support reaction horizontal forces to the perpendicular direction walls and, finally, to their respective foundations. According to the proposed in fig. 13-b, angle bars or steel folded plates should be used together with steel connectors to ensure adequate link between the wood beam and the wall. Eventually, a reinforced concrete tie beam may be used to provide a more regular and efficient connection to the wall.

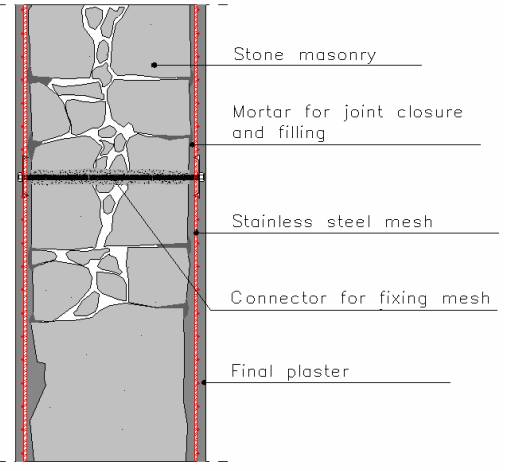

a)

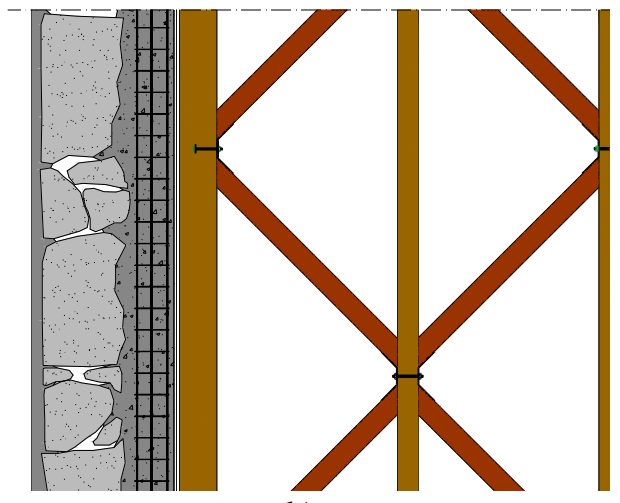

b)

Figure 13 - Wall intervention schemes. a) Strengthening with stainless steel mesh and plaster.

b) Schematic layout for bracing free walls 
Existing floors should be maintained as much as possible, replacing only deteriorated structural and floor elements. This applies for all elements, but with particular emphasis for the main beam. Secondary wood beams supported by the main beam must be duly connected to provide continuity. On the other hand, beams supported by the walls must be properly connected to the later, by recourse to steel devices (made of folded plates or angle bars) and bolts, again to ensure adequate horizontal bracing of the wall.

As for the floors, the roof elements must be in good conditions and firmly connected to the walls. Therefore, they must be inspected and replaced when they do not appear structurally or physically sound. Following a similar procedure as for the floor, the roof wood truss braces should be connected to the bearing walls by means of a steel angle bar or folded plate running all around the building interior perimeter, thereby providing continuity to the corners.

This last strengthening option is shown in the picture of fig. 14, corresponding to the structural intervention on the semi-rural house under study. There can be seen the angle plate supporting the roof braces, that simultaneously helps on confining the top ends of the building walls; note how the plate is fastened to the wall using threaded rods crossing the total wall thickness. Fig. 15 shows the same house partially plastered, in which almost all the referred techniques were applied, and where can be seen the connectors adopted for fixing the steel mesh.

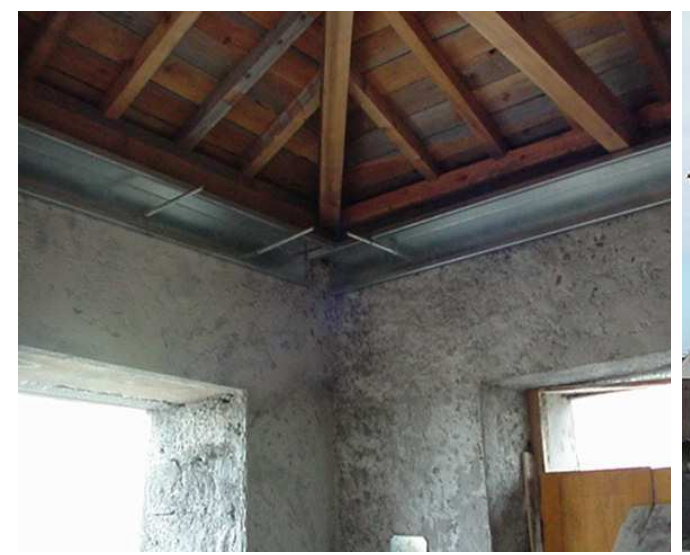

Fig. 14 - Angle plate supporting the roof braces in the semi-rural house

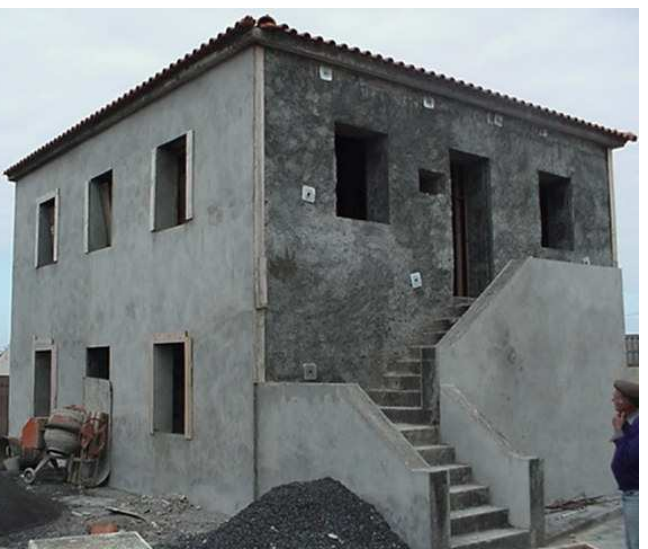

Fig. 15 - Semi-rural house strengthened and partially plastered

\section{CONCLUSIONS}

Having identified the major damage problems caused in small masonry buildings by the 9 July 1998 earthquake in Faial, Azores, repair and strengthening techniques were proposed for the rehabilitation of those buildings whilst maintaining their traditional features.

The main behaviour deficiencies were found to arise, at the global level, from the lack of structural confinement of the building as a whole and, at the local level, from easy loss of masonry walls integrity during a seismic event. These aspects allowed to draw the basics of the proposed intervention that should first reinforce the masonry walls, as the main structural 
resistant elements, and then make use of the existing (or eventually renewed) floors and roofs to promote global bracing of the whole structure.

Such requirements are met within the strengthening schemes proposed herein by using wall reinforcement with a stainless steel mesh placed inside the new exterior and interior plaster covers (connect by steel rods crossing the wall thickness) and by including efficient connections between walls and floors/roofs that are able to perform properly in both principal directions of the structure. Linear elastic numerical simulations in time domain gave support to the design process, considering the seismic action represented by the actually recorded accelerograms during the abovementioned earthquake, and using experimentally obtained and calibrated values of the elasticity modulus $(\mathrm{E}=0.23 \mathrm{GPa})$.

The proposed strategy is believed to ensure building safety during future earthquakes. Although somewhat minimalist, the intervention does fulfil its basic goal by making the best use of existing elements, reinforcing them where necessary and adapting them to their intended structural function.

\section{ACKNOWLEDGEMENTS}

The authors would like to thank all the colleagues who collaborated in this work and the Commission to Promote the Reconstruction of Faial Island (C.P.R.) for the given assistance.

\section{REFERENCES}

[1] Correia Guedes, J. H.; Oliveira, C. S. - Caracterização da Edificação de Alvenaria Tradicional. Elementos para o Estudo do Comportamento e verificação do Parque Habitacional aquando do sismo de 1/1/80 nos Açores.10 anos Após o Sismo de 1 de Janeiro de 1980, Vol.2, Published by Carlos S. Oliveira, Arcindo R. A. Lucas, J. H. Correia Guedes. S. R. H. O. P. LNEC, 1990.

[2] Bastos, A.M.S. - Estudo Experimental do Comportamento de Paredes de Alvenarias de Basalto Sob Acções Estáticas e Dinâmicas, Relatório do Laboratório de Ensaio de Materiais de Construção da Faculdade de Engenharia da Universidade do Porto, 1990.

[3] Costa, A. - Determination of mechanical properties of traditional masonry walls in dwellings of Faial Island, Azores. Earthquake Engineering and Structural Dynamics, Vol 31 Number 7, pg. 1361 - 1382, July 2002.

[4] Costa, A. - Ensaios de Caracterização de Alvenarias Tradicionais. ISBN: 972-98312-0-3. Published by M.M. - Trabalhos de Engenharia Civil, Lda, Porto, 1999.

[5] Clough, R. W.; Penzien, J. - Dynamics of Structures. McGraw-Hill. New York, 1975.

[6] Faria, R. - Avaliação do Comportamento Sísmico de Barragens de Betão Através de um Modelo de Dano Contínuo, PHD, FEUP, Porto, 1995. 
[7] Oliveira, C. S.; Sousa, M. L.; Guedes, J. H. C.; Martins, A.; Campos-Costa, A. - A Crise Sísmica do Faial/Pico/São Jorge Iniciada a 9 de Julho de 1998 Vista na Rede Acelerográfica dos Açores, 1st Symposium on Meteorology and Geophysics by APMG, Lagos, pp. 75-79, 1998.

[8] Ravara, A.; Duarte, R.T.; Carvalho, E.C. - Engenharia Sísmica de Pontes, ICT, Especialização e Aperfeiçoamento. Estruturas. S318, LNEC, Lisbon, 1984.

[9] Costa, A.; Vasconcelos, O. - Reforço de Moradias de Construção Tradicional. Dois Casos Práticos da Ilha do Faial, Sismica 2001 - 5th National Meeting of Seismology and Seismic Engineering, Azores, pp. 593-606, 2001. 